\title{
Study on the Influence of a New Liquid Accelerator on Shotcrete Performance
}

\author{
Luchen Zhang, Shuchen Li, Qin Yan and Lin Zhu \\ Geotechnical and Structural Engineering Research Center, Shandong University, \\ Jinan, Shandong 250061, China
}

\begin{abstract}
Shotcrete is an essential preliminary support means in New Austrian Tunneling Method (NATM) construction and plays a very important role in controlling the stability of surrounding rock. The accelerator is a necessary admixture in shotcrete and its quality can greatly affect shotcrete performance. This paper proposes a new liquid accelerator characterized by short initial and final setting time, small dosage, and good adaptability to cement. Laboratory tests and field tests are conducted to verify the influence of this liquid accelerator on shotcrete performance. Numerical simulation is carried out to study the strength growth of shotcrete with the passage of time and interaction between the strength and stress release of surrounding rock. The results show that the initial and final setting time of this liquid accelerator is with 2 minutes and 4 minutes respectively. Its dosage is only $1.5 \%$ to $4 \%$ of the cement quantity. Adding this liquid accelerator can effectively improve the early strength and reduce the later strength loss of shotcrete, achieving better supporting effects for surrounding rock. During spraying concrete in actual engineering, it is an ideal liquid accelerator for shotcrete, characterized by little resilience, no slurry shedding, and low dust.
\end{abstract}

Keywords: liquid accelerator, shotcrete, primary support, stress release of surrounding rock, numerical simulation

\section{Introduction}

With the construction of large-scale underground engineering in China, shotcrete as a necessary support means is widely used. Shotcrete is a kind of concrete set and hardened from a mix of cement, sand, stone, mineral materials, and admixtures in a proper proportion after being sprayed at high velocity onto a surface (such as the rock, soil layer, building structure or template) through the pipeline via compressed air or other force by using the shotcrete machine. Shotcrete can be quickly hardened to support surrounding rock without manual vibration.

The accelerator is a necessary admixture for shotcrete whose role is to quickly set and harden shotcrete, reduce resilience loss, prevent shotcrete from falling off due to the action of gravity, improve the adaptability of shotcrete to the aquifer, generate higher early strength, and increase the depth of single shotcrete layer ${ }^{[1-2]}$. The accelerator is classified into powdered and liquid accelerator. Its main types include alumina clinkercarbonate series, alumina clinker-alunite series, water glass series, low-alkali or alkalifree series [3-4]. Currently, shotcrete mainly adopts powdered accelerators in China, mainly applied to dry shotcrete, has a large amount of resilience and dust, cannot be uniformly mixed with aggregates, and causes large dosage, therefore seriously affecting the later strength, increasing the construction cost, and retarding the construction progress. The liquid accelerator, mainly applied to wet shotcrete, has instable quality, generally large dosage (6\% to $10 \%$ ), and immature supporting construction technology. Therefore, to resolve the preceding problems, a new liquid accelerator for shotcrete, with the dosage about $2 \%$, has properties in all aspects superior to first-class goods stipulated 
in the JC477-2005 Flash setting admixtures for shotcrete, to better meet construction needs.

The shotcrete containing the accelerator can be set within 2 to 10 minutes after spraying so that it can provide the support resistance (radial force) for surrounding rock in a timely manner, change the biaxial stress status without support to triaxial stress status of the surface rock for the surrounding rock, and improve the strength of surrounding rock. The shotcrete layer is a flexible support and can gradually coordinate with deformations of surrounding rock by adjusting deformations, therefore improving the stress status, reducing the stress, and giving full play to the self-bearing capacity of surrounding rock [5-6]. This paper adopted the numerical simulation method to study the growth of early strength of shotcrete added with the new liquid accelerator with the passage of time as well as interaction between the growth and the stress release of surrounding rock recently excavated, and compare shotcrete added with the traditional and new liquid accelerator on the supporting role.

In this paper, chapter 2 introduces the development thinking, material composition, and functional mechanism of this liquid accelerator. Chapter 3 mainly studies the impact of its ingredients on the properties of cement and concrete through laboratory tests. Chapter 4 mainly studies the effects of support for surrounding rock of shotcrete added with this liquid accelerator, adopts the numerical simulation method to study the impact on surrounding rock supporting effects of shotcrete with varied ages and strength, and considers the interaction between the stress release rate of surrounding rock and shotcrete support. Chapter 5 mainly verifies the performance of this liquid accelerator in actual work via field tests.

\section{Development of Liquid Accelerator}

\subsection{Development Thinking of Liquid Accelerator}

According to a series of studies on specialty chemicals, it can be found that the shotcrete accelerator has a large room for improvement and that the accelerator in the current market has many problems. For example, the powdered accelerator has a serious dust problem and cannot be dissolved and display effects in a just 0.01-second mixing time. Therefore, the surface of shotcrete is hard and most coarse aggregates are rebounded. Moreover, the compressive strength of 28-day (or other ages) shotcrete is not ideal and far from meeting design specifications, which brings potential risks to engineering safety, causes large usage of cement and high construction cost of shotcrete, and therefore is not applicable at all. Currently, the liquid accelerator used onsite is easy to deteriorate and produce precipitate, needs large dosage (generally $6 \%$ to $10 \%$ of the cement quantity), causes serious later strength loss for shotcrete, cannot adapt itself well to cement, and causes a large amount of resilience and slurry shedding in actual field applications. Due to the preceding reasons, the new liquid accelerator is developed.

\subsection{Composition of Liquid Accelerator}

(1) Mother liquor preparation

This liquid accelerator is mainly prepared by $\mathrm{KOH}$ and $\mathrm{Al}(\mathrm{OH})_{3}$ in a certain mole ratio, with the mole ratio of potassium to aluminum below 1.2. A certain amount of $\mathrm{KOH}$ and $\mathrm{Al}(\mathrm{OH})_{3}$ solid powder is weighed, poured into a three-necked flask, and reacted with added quantitative water. The temperature is controlled above $120^{\circ} \mathrm{C}$, and the electric stirring rod is used to constantly stir the liquid during the reaction. The reaction time is 2 hours and then the aluminate mother liquor is available. The obtained mother liquor is filtered and the uniform and stable solution is obtained.

(2) Mother liquor compounding 
After the mother liquor is obtained, to improve its performance, other components are added to compound the mother liquor, including the polyacrylamide, triethanolamine, water reducing admixture, lithium salt, and stabilizer. This mother liquor is a kind of aluminate accelerator featuring small dosage and better coagulating effects. However, the single solution cannot meet various requirements of shotcrete and therefore the mother liquor is compounded. Polyacrylamide is a kind of thickener used mainly to increase the cohesiveness of shotcrete and reduce resilience during construction; triethanolamine is a kind of early strength agent that can shorten the setting time; the water reducing admixture is mainly to reduce water consumption and improve shotcrete strength; lithium salt can inhibit the alkali-aggregate reaction of shotcrete; Stabilizer can effectively improve the stability of the accelerator.

\subsection{Functional Mechanism of Liquid Accelerator}

As a kind of compound aluminate accelerator, this liquid accelerator has the mole ratio of potassium to aluminum below 1.2 and its active ingredient is mainly aluminate ion. Increasing the content of aluminate ion in the solution can give better play to accelerating effects. Meanwhile, reducing the mole ratio of potassium to aluminum can reduce the alkalinity of the accelerator and inhibit the alkali-aggregate reaction of shotcrete.

The main component of this liquid accelerator is $\mathrm{KAl}(\mathrm{OH})_{4}$. Given $\mathrm{Ca}(\mathrm{OH})_{2}$, it reacts with gypsum in cement to produce calcium sulphoaluminate hydrates (ettringite) as well as potassium hydroxide and significantly reduces the concentration of soluble gypsum for delayed coagulation in cement mortar. Now, $\mathrm{C}_{3} \mathrm{~A}$, a cement mineral component, is quickly dissolved into the solution and hydrated to hexagonal $\mathrm{C}_{3} \mathrm{AH}_{6}$ plates, thus accelerating the setting of cement mortar. A large amount of heat of hydration produced by the preceding reactions will also promote the reaction process and strength development. In addition, in the initial hydration stage, those ingredients produced in the solution such as $\mathrm{Ca}(\mathrm{OH})_{2}, \mathrm{SO}_{4}{ }^{2-}$, and $\mathrm{Al}_{2} \mathrm{O}_{3}$ combine to produce high-sulfur calcium sulphoaluminate hydrate (ettringite) that is not only conducive to the development of early strength but also reduces the concentration of $\mathrm{Ca}(\mathrm{OH})_{2}$, thus facilitating the hydration of $\mathrm{C}_{3} \mathrm{~S}$. The produced calcium silicate hydrate gel interlaps to form crystals with the grid structure, thus boosting condensation [7-16].

\section{Experimental Studies on Material Properties}

\subsection{Experimental Material}

The test cement adopts $425 \#$ ordinary Portland cement, with the main components listed in Table 1.

Table 1. Main Components of Cement

\begin{tabular}{cccc}
\hline Components & Chemical formula & $\begin{array}{c}\text { Shorthand } \\
\text { notation }\end{array}$ & $\begin{array}{c}\text { Mass } \\
\text { fraction/\% }\end{array}$ \\
\hline $\begin{array}{c}\text { Tricalcium } \\
\text { silicate } \\
\text { Dicalcium } \\
\text { silicate }\end{array}$ & $3 \mathrm{CaO} \cdot \mathrm{SiO}_{2}$ & $\mathrm{C}_{3} \mathrm{~S}$ & 17.83 \\
$\begin{array}{c}\text { Tricalcium } \\
\text { aluminate }\end{array}$ & $2 \mathrm{CaO} \cdot \mathrm{SiO}_{2}$ & $\mathrm{C}_{2} \mathrm{~S}$ & 55.24 \\
$\begin{array}{c}\text { Tetra-calcium } \\
\text { aluminoferrite }\end{array}$ & $4 \mathrm{CaO} \cdot \mathrm{Al}_{2} \mathrm{O}_{3} \cdot \mathrm{Al}_{2} \mathrm{O}_{3} \mathrm{O}_{3}$ & $\mathrm{C}_{4} \mathrm{AF}$ & 7.81 \\
$\begin{array}{c}\text { Calcium sulphate } \\
\text { dihydrate }\end{array}$ & $\mathrm{CaSO}_{4} \cdot 2 \mathrm{H}_{2} \mathrm{O}$ & $\mathrm{CSH}_{2}$ & 8.0 \\
\hline
\end{tabular}




\subsection{Test Method}

(1) Refer to the JC477-2005 Flash setting admixtures for shotcrete standard (hereinafter referred to as the Standard) in the building material industry.

(2) Get $400 \mathrm{~g}$ cement with the water-cement ratio of 0.4 . The additive amount of water needs to deduct the water content in the liquid accelerator. The normal consistency and setting time tester of neat cement paste is adopted to measure the initial and final setting time of neat cement paste with different dosages. Different reagents are added to compound it and then the initial and final setting time is measured.

(3) Get $900 \mathrm{~g}$ cement and $1350 \mathrm{~g}$ standard sand, with the water-cement ratio of 0.5 , mix the mortar uniformly, add the liquid accelerator, and quickly stir the cement mortar for 40 to 50 seconds. Make a $40 \mathrm{~mm} \times 40 \mathrm{~mm}$ x $160 \mathrm{~mm}$ trial model with cement mortar, maintain it in the standard curing room at the temperature of $20^{\circ} \mathrm{C} \pm 2^{\circ} \mathrm{C}$ and with humidity above $95 \%$, measure its strength after one day or 28 days, and calculate the strength ratio.

\subsection{Test Results and Analysis}

(1) Measurement of the setting time of cement with different dosages

The liquid accelerator has different setting time with different dosages. Figure 1 shows the initial and final setting time of neat cement paste with different dosages of this liquid accelerator, with a certain water-cement ratio of 0.4 .

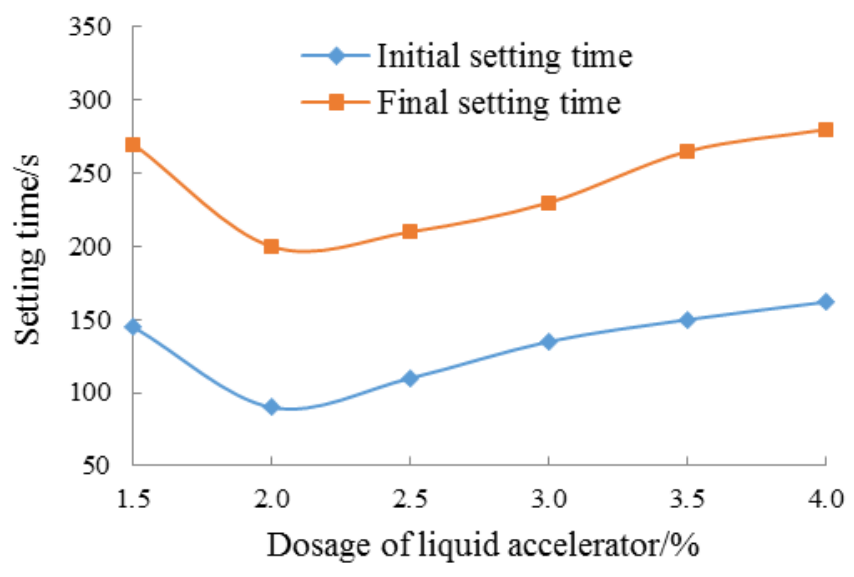

\section{Figure 1. Dosage Change Curves of Initial and Final Setting Time}

Figure 1 shows that this liquid accelerator has the best accelerating effects when the dosage is $2 \%$. The initial and final setting time is 1 min30s and 3 min20s respectively, which meets the requirements of first-class goods stipulated in the Standard. With increasing dosage, the setting time is delayed on the contrary. Indicating that the liquid accelerator has an optimal dosage, it is not that more accelerators make better accelerating effects.

Whether the accelerator can quickly condense and harden cement also depends on accelerator adaptability to cement mineral compositions and gypsum types instead of all depending on accelerator dosage. As there are many interacting internal and external factors affecting accelerator adaptability to cement, the mechanism is very complex. Therefore, the optimal accelerator dosage can only be the result of the adaptability test conducted on the used cement and accelerator in a proper water-cement ratio range and at a certain ambient temperature. A dosage lower or higher than the optimal will prevent the accelerator from playing its proper role in shotcrete application.

(2) Measurement of the setting time of cement with different water-cement ratios 
The water-cement ratio can also greatly affects the cement setting time. Figure 2 shows the initial and final setting time of cement with different water-cement ratios and the same accelerator dosage, $2 \%$.

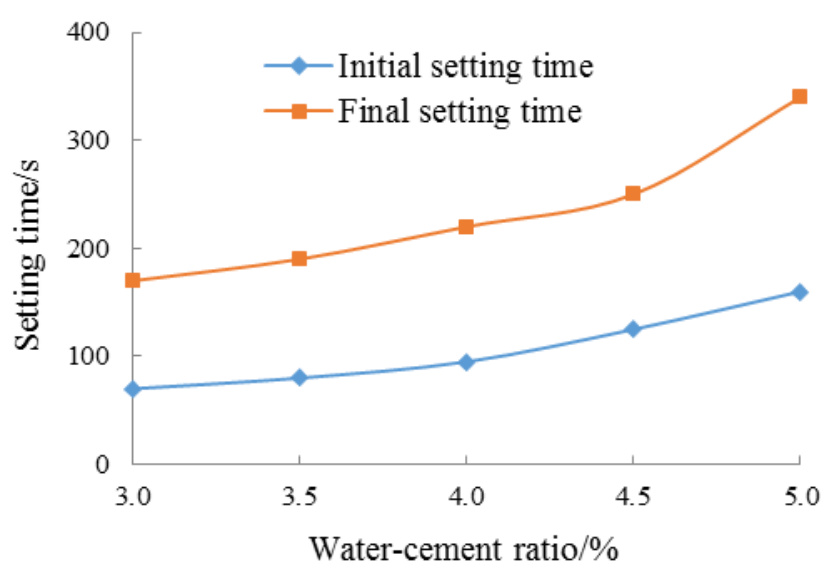

Figure 2. Water-Cement Ratio Change Curves of Initial and Final Setting Time

According to Figure 2, as the water-cement ratio increases, the initial and final setting time is prolonged. Indicating that the greater the water-cement ratio, the worse the accelerating effects. In dry-mix shotcrete, the water-cement ratio is controlled by adjusting the water volume by the shotcrete manipulator based on his observation. The mixture water consumption in dry shotcrete should not only make the shotcrete have better compaction and adhesiveness but also reduce resilience materials. A too large water-cement ratio usually causes shotcrete to fall off while a too small water-cement ratio causes stratification to mixtures. In wet-mix shotcrete, the water-cement ratio is specific and needs to meet properties such as the slump and pumpability.

(3) Impact of the accelerator with different dosages on the strength of cement mortar

The compressive strength of cement mortar with different dosages is obtained. As the accelerator dosage increases, the later strength loss tends to increase. However, if the dosage ranges from $1.5 \%$ to $4 \%$, the later strength loss will not exceed $10 \%$. Table 2 shows the compressive strength of cement mortar.

Table 2. Compressive Strength of Cement Mortar

\begin{tabular}{cccc}
\hline \multirow{2}{*}{ Accelerator dosage/\% } & \multicolumn{2}{c}{ Compressive strength/MPa } & 28d compressive strength ratio/\% \\
\cline { 2 - 3 } & $1 \mathrm{~d}$ & $28 \mathrm{~d}$ & 100 \\
\hline 0 & 7.8 & 47.8 & 98.1 \\
2.5 & 13.6 & 46.9 & 96.4 \\
2.0 & 13.9 & 46.1 & 94.1 \\
3.0 & 14.5 & 45 & 93.3 \\
3.5 & 15.1 & 44.6 & 91.4 \\
4.0 & 15.8 & 43.7 & 90.2 \\
\hline
\end{tabular}




\section{Numerical Calculation}

\subsection{Strength-Time Curve of Shotcrete}

In the lab, the hardening characteristics of shotcrete are tested. Shotcrete adopts C25 mix proportion (selected from Changgang tunnel of Fushou Highway) of cement, sand, to stone as 469:912:912. Non-linear regression analysis is conducted on shotcrete strength and time, and then the change rules between the strength and age are obtained. Table 3 lists the uniaxial compressive strength of shotcrete added with the traditional accelerator. Figure 3 shows the strength-time regression curve of shotcrete added with the traditional accelerator.

Table 3. Uniaxial Compressive Strength of Shotcrete Added with the Traditional Accelerator

\begin{tabular}{ccccccc}
\hline $\begin{array}{c}\text { Age } \\
\begin{array}{c}\text { Specimen } \\
\text { No. }\end{array}\end{array}$ & $8 \mathrm{~h} / \mathrm{MPa}$ & $12 \mathrm{~h} / \mathrm{MPa}$ & $1 \mathrm{~d} / \mathrm{MPa}$ & $3 \mathrm{~d} / \mathrm{MPa}$ & $7 \mathrm{~d} / \mathrm{MPa}$ & $28 \mathrm{~d} / \mathrm{MPa}$ \\
\hline 1 & 4.35 & 6.80 & 9.52 & 14.6 & 21.89 & 25.4 \\
2 & 5.05 & 7.22 & 10.25 & 15.40 & 20.76 & 26.38 \\
3 & 4.92 & 6.95 & 9.80 & 14.88 & 22.12 & 27.10 \\
4 & 4.36 & 6.50 & 9.30 & 15.72 & 23.30 & 26.70 \\
5 & 4.8 & 7.10 & 10.64 & 16.20 & 21.66 & 25.89 \\
6 & 4.45 & 6.83 & 9.13 & 14.67 & 23.20 & 27.80 \\
7 & 4.82 & 7.25 & 10.37 & 15.60 & 21.37 & 28.31 \\
8 & 6.15 & 7.64 & 11.28 & 16.38 & 22.50 & 29.25 \\
9 & 5.20 & 7.30 & 9.95 & 14.68 & 21.86 & 27.97 \\
\hline
\end{tabular}

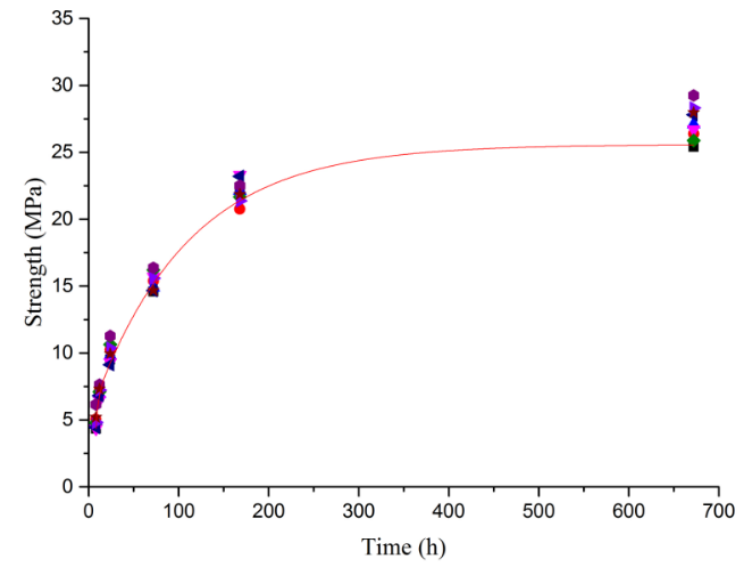

Figure 3. Strength-Time Regression Curve of Shotcrete Added with the Traditional Accelerator

The researcher obtained the following formula of elasticity modulus obtained via tests and shotcrete compressive strength [17]:

$$
E_{C}=\frac{10^{5}}{A+\frac{B}{f_{c u}}}
$$

The fitted values of A and B can be obtained by fitting shotcrete elasticity modulus (listed in Table 4) and uniaxial compressive strength by using formula (1) according to 
the GB50086-2001 Specifications for bolt-shotcrete support. Formula (2) for the relation between shotcrete and compressive strength can be obtained by using formula (1).

\section{Table 4. Standard Values of Shotcrete Elasticity Modulus and Uniaxial} Compressive Strength

\begin{tabular}{c|cccc}
\hline $\begin{array}{c}\text { Shotcrete strength grade } \\
\text { Elasticity modulus }\end{array}$ & $\mathrm{C} 15 / \mathrm{MPa}$ & $\mathrm{C} 20 / \mathrm{MPa}$ & $\mathrm{C} 25 / \mathrm{MPa}$ & $\mathrm{C} 30 / \mathrm{MPa}$ \\
Uniaxial compressive strength & $1.8 \times 10^{4}$ & $2.1 \times 10^{4}$ & $2.3 \times 10^{4}$ & $2.5 \times 10^{4}$ \\
& 15.0 & 20.0 & 25.0 & 30.0 \\
\hline$E_{C}=\frac{10^{5}}{2.46+\frac{46.12}{f_{c u}}}$
\end{tabular}

Table 5 lists the elasticity modulus of shotcrete added with the traditional accelerator obtained by using formula (2). Figure 4 shows the elasticity modulus-time regression curve of shotcrete added with the traditional accelerator.

Table 5. Elasticity Modulus of Shotcrete Added with the Traditional Accelerator

\begin{tabular}{ccccccc}
\hline $\begin{array}{r}\text { Age } \\
\text { Specimen No. }\end{array}$ & $8 \mathrm{~h} / \mathrm{GPa}$ & $12 \mathrm{~h} / \mathrm{GPa}$ & $1 \mathrm{~d} / \mathrm{GPa}$ & $3 \mathrm{~d} / \mathrm{GPa}$ & $7 \mathrm{~d} / \mathrm{GPa}$ & $28 \mathrm{~d} / \mathrm{GPa}$ \\
\hline 1 & 7.66 & 10.82 & 13.69 & 17.80 & 21.90 & 23.39 \\
2 & 8.63 & 11.30 & 14.37 & 18.33 & 21.36 & 23.76 \\
3 & 8.45 & 10.99 & 13.95 & 17.99 & 22.00 & 24.03 \\
4 & 7.67 & 10.47 & 13.48 & 18.54 & 22.53 & 23.88 \\
5 & 8.29 & 11.17 & 14.72 & 18.84 & 21.79 & 23.58 \\
6 & 7.80 & 10.85 & 13.31 & 17.84 & 22.48 & 24.28 \\
7 & 8.31 & 11.34 & 14.48 & 18.46 & 21.65 & 24.46 \\
8 & 10.04 & 11.77 & 15.27 & 18.96 & 22.17 & 24.77 \\
9 & 8.83 & 11.39 & 14.09 & 17.85 & 21.88 & 24.34 \\
\hline
\end{tabular}

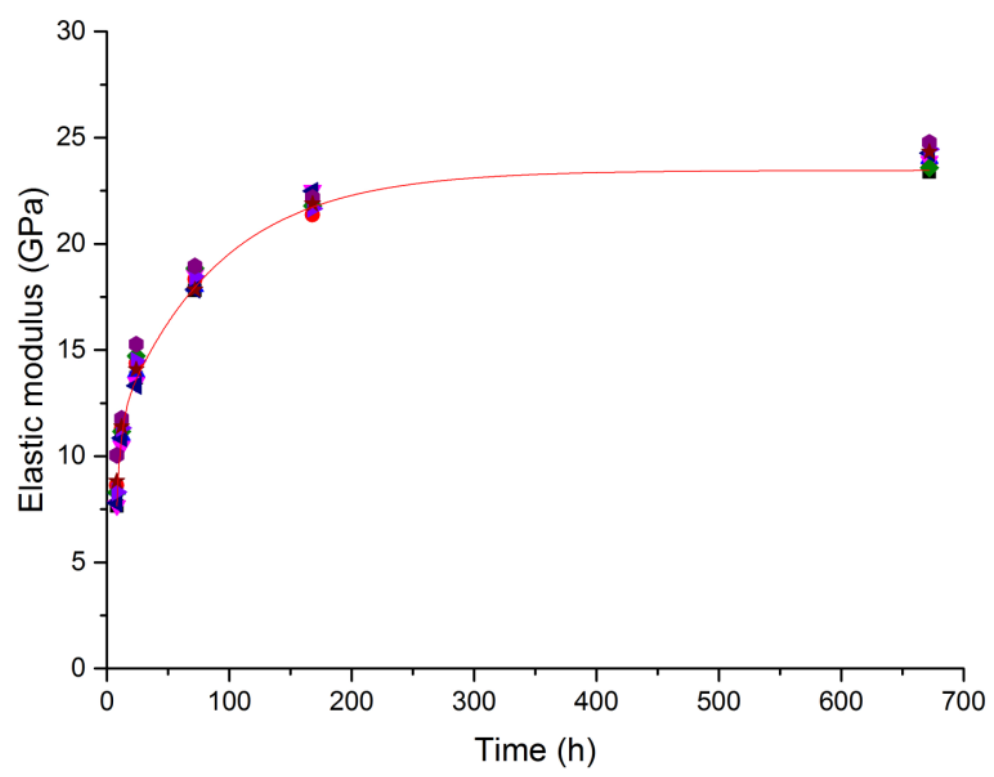

Figure 4. Elasticity Modulus-Time Regression Curve of Shotcrete Added with the Traditional Accelerator 
(1) Strength-time regression curve of shotcrete added with the traditional accelerator

$$
F_{c}(t)=25.6\left(1-1.85 \mathrm{e}^{-0.38 \mathrm{t}}-0.8 \mathrm{e}^{-0.009 \mathrm{t}}\right)
$$

(2) Elasticity modulus-time regression curve of shotcrete added with the traditional accelerator

$$
E(t)=23.5\left(1-1.5 \mathrm{e}^{-0.274 t}-0.56 \mathrm{e}^{-0.012 t}\right)
$$

Table 6 lists the uniaxial compressive strength of shotcrete added with the new liquid accelerator. Figure 5 shows the strength-time regression curve of shotcrete added with the new liquid accelerator.

\section{Table 6. Uniaxial Compressive Strength of Shotcrete Added with the New Liquid Accelerator}

\begin{tabular}{ccccccc}
\hline $\begin{array}{c}\text { Age } \\
\text { Specimen No. }\end{array}$ & $8 \mathrm{~h} / \mathrm{MPa}$ & $12 \mathrm{~h} / \mathrm{MPa}$ & $1 \mathrm{~d} / \mathrm{MPa}$ & $3 \mathrm{~d} / \mathrm{MPa}$ & $7 \mathrm{~d} / \mathrm{MPa}$ & $28 \mathrm{~d} / \mathrm{MPa}$ \\
\hline 1 & 7.25 & 8.99 & 12.75 & 19.39 & 27.48 & 31.06 \\
2 & 7.37 & 9.53 & 14.15 & 20.12 & 26.66 & 31.66 \\
3 & 7.34 & 9.71 & 13.29 & 19.72 & 27.97 & 32.60 \\
4 & 6.38 & 9.18 & 12.76 & 20.30 & 28.69 & 32.18 \\
5 & 7.18 & 9.47 & 14.59 & 20.86 & 27.65 & 31.88 \\
6 & 7.01 & 8.95 & 12.80 & 19.28 & 28.44 & 33.17 \\
7 & 7.35 & 9.73 & 13.53 & 19.89 & 27.11 & 34.21 \\
8 & 8.16 & 9.98 & 14.33 & 20.97 & 27.84 & 34.95 \\
9 & 7.46 & 10.27 & 13.45 & 19.17 & 27.72 & 33.65 \\
\hline
\end{tabular}

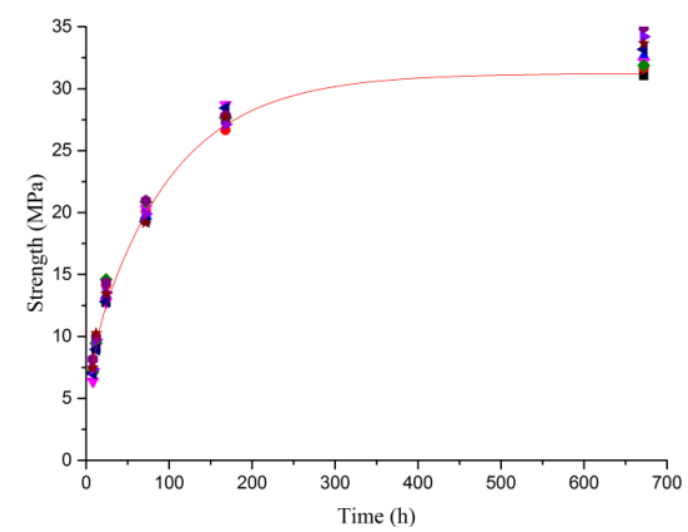

Figure 5. Strength-Time Regression Curve of Shotcrete Added with the New Liquid Accelerator

Table 7 lists the elasticity modulus of shotcrete added with the new liquid accelerator. Figure 6 shows the elasticity modulus-time regression curve of shotcrete added with the new liquid accelerator. 


\section{Table 7. Elasticity Modulus of Shotcrete Added with the New Liquid} Accelerator

\begin{tabular}{ccccccc}
\hline $\begin{array}{c}\text { Age } \\
\text { Specimen No. }\end{array}$ & $8 \mathrm{~h} / \mathrm{GPa}$ & $12 \mathrm{~h} / \mathrm{GPa}$ & $1 \mathrm{~d} / \mathrm{GPa}$ & $3 \mathrm{~d} / \mathrm{GPa}$ & $7 \mathrm{~d} / \mathrm{GPa}$ & $28 \mathrm{~d} / \mathrm{GPa}$ \\
\hline 1 & 11.33 & 13.17 & 16.45 & 20.67 & 24.16 & 25.35 \\
2 & 11.47 & 13.70 & 17.48 & 21.04 & 23.87 & 25.53 \\
3 & 11.44 & 13.87 & 16.86 & 20.84 & 24.34 & 25.81 \\
4 & 10.32 & 13.36 & 16.47 & 21.13 & 24.58 & 25.69 \\
5 & 11.25 & 13.65 & 17.79 & 21.41 & 24.22 & 25.60 \\
6 & 11.06 & 13.13 & 16.49 & 20.61 & 24.50 & 25.97 \\
7 & 11.45 & 13.89 & 17.04 & 20.93 & 24.03 & 26.26 \\
8 & 12.33 & 14.12 & 17.61 & 21.46 & 24.29 & 26.46 \\
9 & 11.57 & 14.38 & 16.98 & 20.55 & 24.25 & 26.11 \\
\hline
\end{tabular}

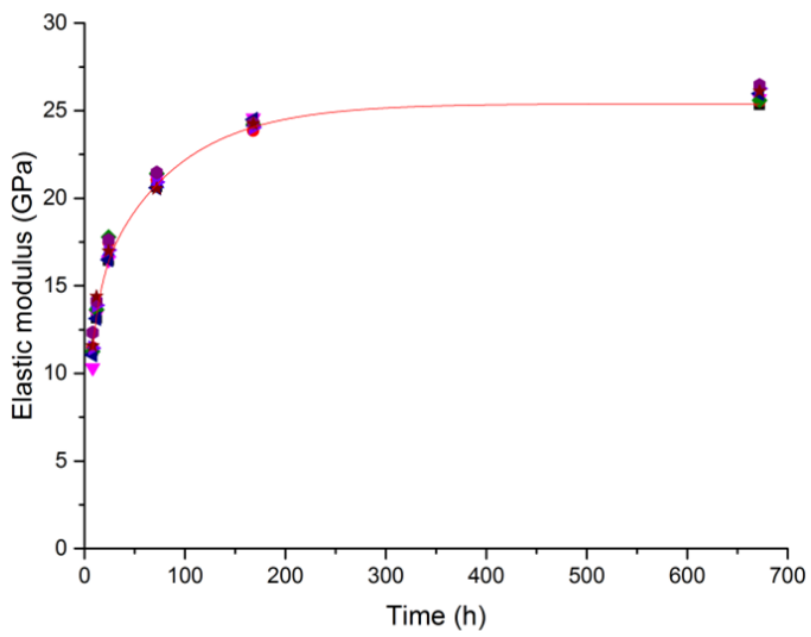

Figure 6. Elasticity Modulus-Time Regression Curve of Shotcrete Added with the New Liquid Accelerator

(1) Strength-time regression curve of shotcrete added with the new liquid accelerator

$$
F_{c}(t)=31.2\left(1-0.27 e^{-0.18 t}-0.77 e^{-0.01 t}\right)
$$

(2) Elasticity modulus-time regression curve of shotcrete added with the new liquid accelerator

$$
E(t)=25.4\left(1-0.39 \mathrm{e}^{-0.127 t}-0.46 \mathrm{e}^{-0.013 \mathrm{t}}\right)
$$

\subsection{Model Building and Parameter Selection}

(1) Mechanical Parameter

Numerical simulation adopts FLAC3D numerical software to study the cross section of class IV surrounding rock of Changgang tunnel, Fushou Highway and consider the stress release rate of surrounding rock. The model dimension is twice of the diameter that is 12 $\mathrm{m}$. Both surrounding rock and preliminary support adopt solid elements. Normal restraint is set on the lateral boundary and full restraint is set on the surface boundary of the model. Considering the hardening characteristics of shotcrete with the passage of time, set Poisson's ratio to 0.2 and volume density to $2300 \mathrm{~kg} / \mathrm{m}^{3}$. Table 8 lists the physical and mechanical parameters of the selected surrounding rock. 
Table 8. Physical and Mechanical Parameters of Surrounding Rock

\begin{tabular}{cccccc}
\hline $\begin{array}{c}\text { Surrounding } \\
\text { rock class }\end{array}$ & $\begin{array}{c}\text { Unit } \\
\text { weight } \\
\left(\mathrm{KN} / \mathrm{m}^{3}\right)\end{array}$ & $\begin{array}{c}\text { Deformation } \\
\text { modulus } \\
/ \mathrm{GPa}\end{array}$ & $\begin{array}{c}\text { Poisson's } \\
\text { ratio }\end{array}$ & $\begin{array}{c}\text { Cohesion } \\
/ \mathrm{MPa}\end{array}$ & $\begin{array}{c}\text { Internal } \\
\text { friction } \\
\text { angle }^{\circ}\end{array}$ \\
\hline $\mathrm{IV}$ & 20 & 1.3 & 0.3 & 0.2 & 27 \\
\hline
\end{tabular}

(2) Stress release rules of surrounding rock

According to the NATM theory, after tunnel excavation, the stress of surrounding rock is gradually released with the passage of time under the action of the self-stabilization capacity of surrounding rock instead of being immediately released. Document [18] proposed the following expression of the load released by tunnel with the passage of time based on numerical simulation results:

Where: $m=\frac{3.15 \mathrm{~V}}{2 a}$

$$
p(t)=p_{0}\left(1-0.7 e^{-m t}\right)
$$

$V$ — tunnel excavation progress, $\mathrm{m} / \mathrm{h}$

$a$ _ tunnel excavation radius, $\mathrm{m}$

$t$ - tunnel excavation time, $\mathrm{h}$

This formula can be used to resolve the following formula of stress release rate of surrounding rock:

$$
n=1-0.7 e^{-m t}
$$

This calculation adopts the preceding stress release rules of surrounding rock and simulates surrounding rock release of this expansive loess tunnel. Therefore, $V=\frac{1}{6} m / h$ , $a=6 \mathrm{~m}$, thus determining that the curve of surrounding rock release rules is as shown in Figure 7.

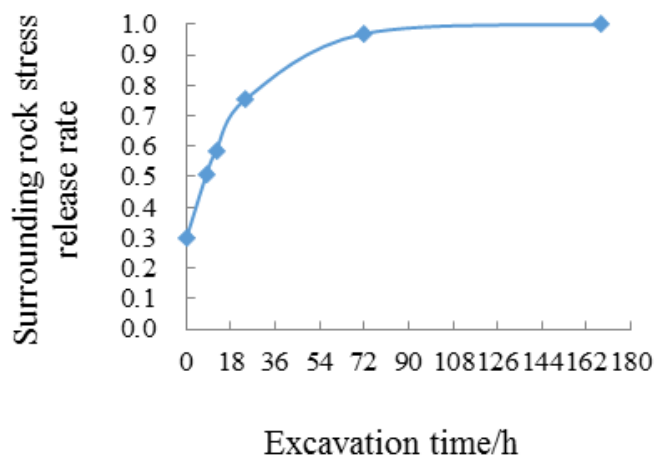

Figure 7. Surrounding Rock Release Rules

\subsection{Calculation Result Analysis}

(1) Largest vault settlement displacement

The shotcrete added with the traditional and new liquid accelerator respectively is studied. Figure 8 shows the largest displacement of vault settlement when the shotcrete added with the conventional and new liquid accelerator respectively interacts with surrounding rock with the passage of time.

According to Figure 8, the largest vault settlement displacement of surrounding rock when the shotcrete added with the new liquid accelerator interacts with surrounding rock 
is smaller than that when the shotcrete added with the traditional accelerator interacts with surrounding rock, indicating that the shotcrete added with the new liquid accelerator has better supporting effects for surrounding rock. Take an average of the largest settlement displacements of $8 \mathrm{~h}, 12 \mathrm{~h}, 1 \mathrm{~d}, 3 \mathrm{~d}, 7 \mathrm{~d}$, and $28 \mathrm{~d}$ surrounding rock. This value is 3.59 when the traditional accelerator is used while it is 2.66 when the new liquid accelerator is added, which improves supporting effects by $26 \%$.

In the first three days of shotcrete support, the largest vault displacement of surrounding rock keeps growing. That is because the tunnel surrounding rock releases stress and forms new stress equilibrium. The release process is accompanied with vault settlement. From 0 to $72 \mathrm{~h}$, the largest vault displacement is $3.17 \mathrm{~mm}$ during spraying concrete support added with the traditional accelerator while that is $1.84 \mathrm{~mm}$ during spraying concrete support added with the new liquid accelerator, with the change rate decreased by $42 \%$. Three days later, stress release of surrounding rock is reduced; meanwhile, the vault settlement is reduced and surrounding rock tends to be stable due to the support. On the 28th day, the largest settlement displacement is $3.82 \mathrm{~mm}$ during spraying concrete support added with the traditional accelerator while that is $2.41 \mathrm{~mm}$, reduced by $37 \%$, during spraying concrete support added with the new liquid accelerator.

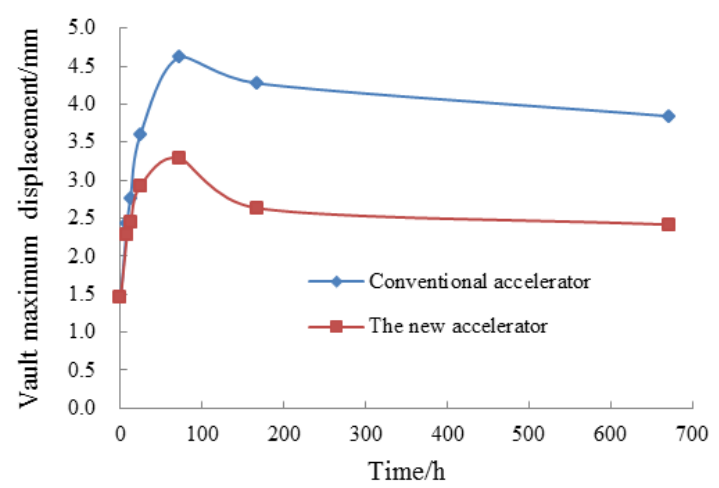

Figure 8. Largest Vault Settlement Displacement

(2) Distribution of surrounding rock plastic zones

$12 \mathrm{~h}, 1 \mathrm{~d}$, and $3 \mathrm{~d}$ plastic zones are selected to study the development of plastic zones of surrounding rock supported by different kinds of shotcrete.

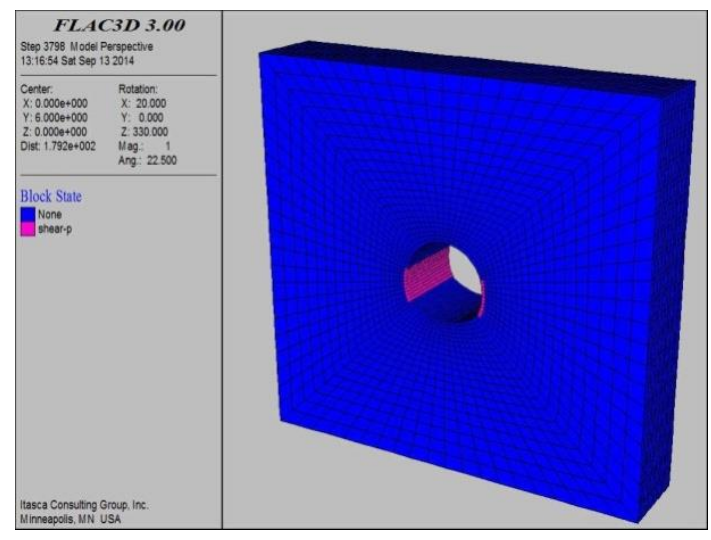

Figure 9. 12h Traditional Support Plastic Zone 


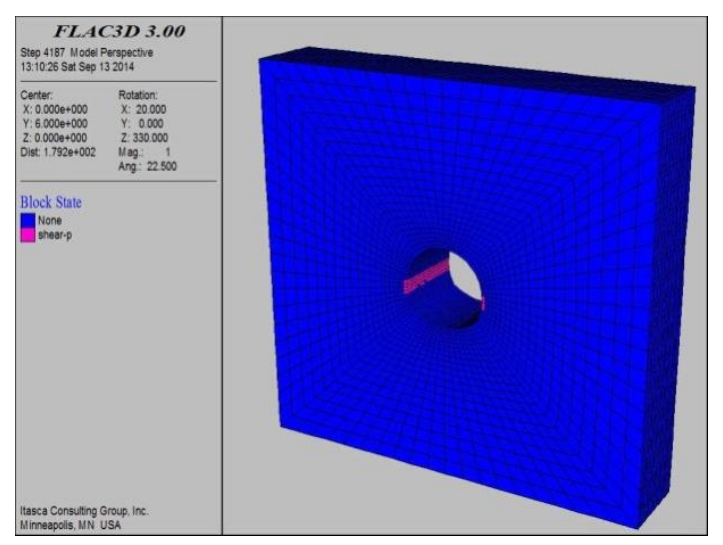

Figure 10. 12h New Support Plastic Zone

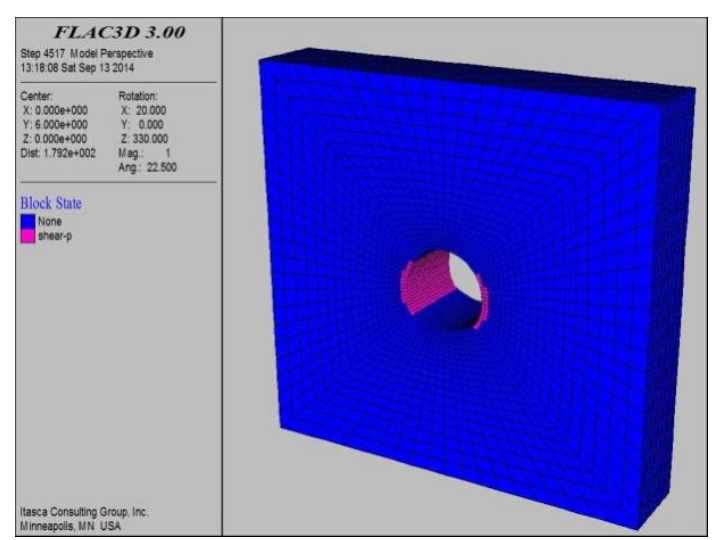

Figure 11. 1d Traditional Support Plastic Zone

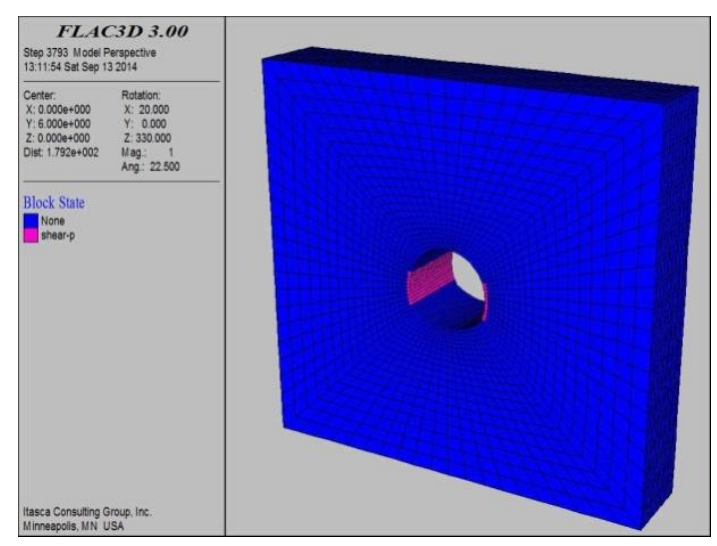

Figure 12. 1d New Support Plastic Zone 


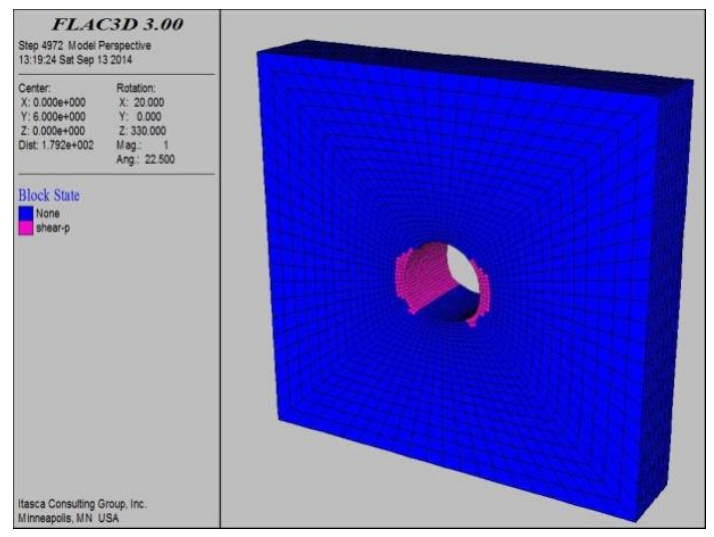

Figure 13. 3d Traditional Support Plastic Zone

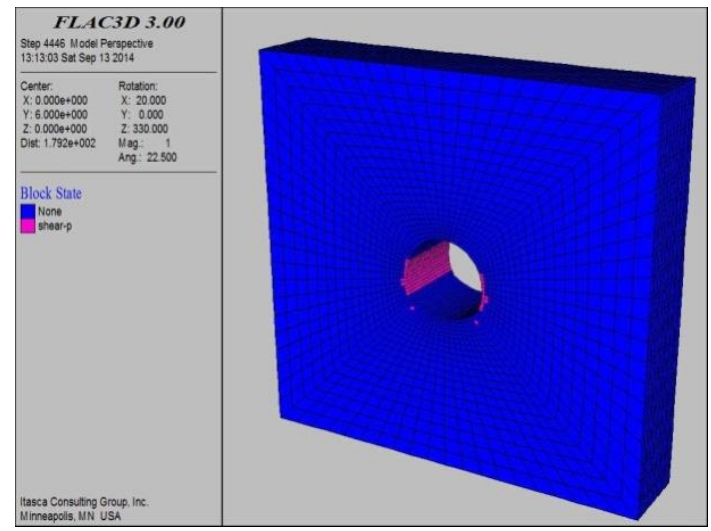

Figure 14. 3d New Support Plastic Zone

According to analysis on Figure 9 to 14, the surrounding rock plastic zones are mainly distributed on the cavern haunch and side wall. With the passage of time, the plastic zone gradually extends to the tunnel deep and arch springing. It also can be seen from the figures that the plastic zone of surrounding rock supported by shotcrete added with new liquid accelerator is obviously smaller than that of surrounding rock supported by shotcrete added with the traditional accelerator.

\section{Engineering Application}

\subsection{Project Overview}

The field test is conducted on the developed new liquid accelerator in Changgang tunnel of Fushou Highway. This tunnel is class IV surrounding rock; the strength grade of shotcrete is designed to C25 and the shotcrete layer depth to $25 \mathrm{~cm}$. The field shotcrete adopts Hong Xing-1 powdered accelerator; the dry jet machine adopts $7 \mathrm{~m}^{3}$; the actual amount of sprayed concrete per hour is about $5 \mathrm{~m}^{3}$. The dry powdered accelerator has the actual dosage reaching 10\%, about 30\% resilience, and large amount of dust during spraying. Figure 15 shows the field dry sprayed concrete. 


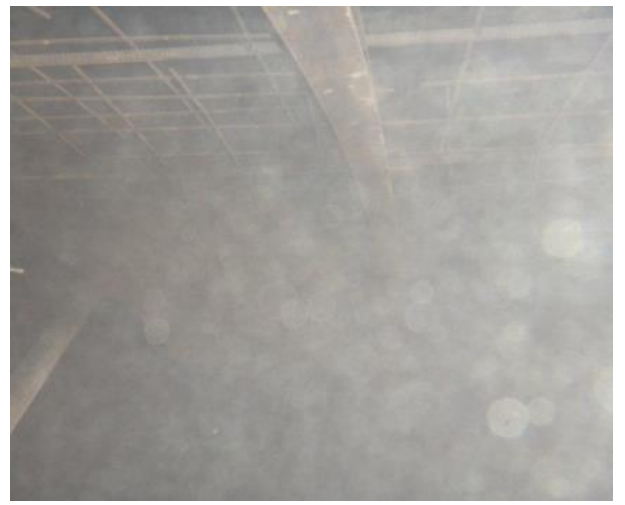

Figure 15. Field Dry Sprayed Concrete

\subsection{Field Shotcrete Test}

(1) Cement: 425\# ordinary Portland cement.

Fine aggregate: used in the test is hard medium-coarse sand with the fineness modulus greater than 2.5. The proportion of particles with the diameter less than $0.075 \mathrm{~mm}$ among sand cannot be exceed $20 \%$.

Coarse aggregate: used in the test is crushed stone with the particle diameter ranging from 5 to $10 \mathrm{~mm}$.

(2) The concrete mix proportion of cement, sand, to stone as $469 \mathrm{~kg}$ : $912 \mathrm{~kg}: 912 \mathrm{~kg}$, the water-cement ratio is designed to 0.45 .

(3) The dosage of the liquid accelerator is designed to $1.5 \%$ during spraying on the side wall and that is designed to $2.5 \%$ during spraying on the vault. Given a larger dosage, the cohesiveness of shotcrete becomes better and slurry shedding can hardly happen. The dosage is controlled by the high-pressure dosing device.

This liquid accelerator is used together with a matching shotcrete method. Based on the original dry-mix shotcrete technology, a high-pressure accelerator dosing device is added, which can provide 1.2 MPa pressure to pump the liquid accelerator to the high-pressure water pipe and accurately control the dosage of the liquid accelerator. The mixture of the liquid accelerator and water contacts with the concrete mix at the nozzle and are sprayed to the surface together.

Using the new liquid accelerator and matching spraying technology, the dust and resilience in the tunnel are relatively little. The pull canvas is adopted to measure resilience and the resilience rate is $8 \%$. The sprayed surface has bright luster, without slurry shedding. Figure 16 shows the liquid accelerator matching spraying technology.

During field spraying concrete, the jet molding test is conducted to measure the strength of shotcrete. The specimen is a $150 \mathrm{~mm}^{3}$ cube template that is grounded flush after tunnel shotcrete. Then, it is maintained in the lab incubator and the $1 \mathrm{~d}, 7 \mathrm{~d}$, and $28 \mathrm{~d}$ uniaxial compressive strength are measured, as listed in Table 9. The test results show that shotcrete using this liquid accelerator has a higher compressive strength. 


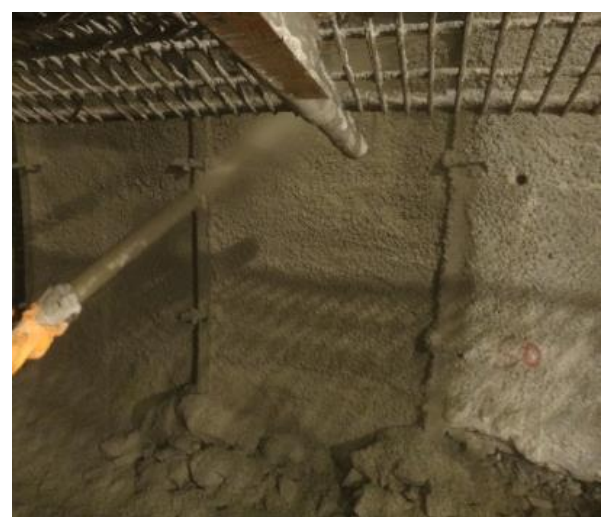

Figure 16. The Liquid Accelerator Matching Spraying Technology

Table 9. Compressive Strength of Shotcrete

\begin{tabular}{ccccc}
\hline $\begin{array}{c}\text { Specimen } \\
\text { SN }\end{array}$ & Age/d & Bearing area/mm & \multicolumn{2}{c}{ Compressive strength $f_{c u} / \mathrm{MPa}$} \\
Single block value & Group value \\
\hline 1 & & 22500 & 13.4 & \\
2 & 1 & 22500 & 12.5 & 12.6 \\
3 & & 22500 & 11.9 & \\
1 & & 22500 & 27.8 & 27.1 \\
2 & 7 & 22500 & 26.9 & \\
3 & & 22500 & 26.6 & 32.4 \\
1 & & 22500 & 33.5 & \\
2 & 28 & 22500 & 31.6 & \\
3 & & 22500 & 32.2 & \\
\hline
\end{tabular}

\section{Conclusion}

(1) The dosage of this liquid accelerator is small, only from $1.5 \%$ to $4 \%$, and it is an efficient compound liquid accelerator. When the dosage is $2 \%$, the quick setting effects are optimal. The initial and final setting time of neat cement paste is within 2 minutes and 4 minutes respectively. It is also a kind of uniform and stable liquid without crystals and precipitate produced, slightly affected by the ambient and well adaptive to cement.

(2) This liquid accelerator contains the thickening components that increase the cohesiveness of shotcrete and can effectively reduce resilience and dust during shotcrete. Meanwhile, it can increase the strength of adhesion with surrounding rock, be adhered to the sprayed surface comprehensively and solidly, and achieve better supporting effects.

(3) This liquid accelerator can effectively reduce the later strength loss of shotcrete and ensure that the strength loss is controlled within $10 \%$. Adding this liquid accelerator can improve the strength of shotcrete at each age and effectively inhibit the development of displacement and plastic zones of surrounding rock. In the numerical simulation analysis of the relationship between shotcrete and surrounding rock support, the strength growth of shotcrete and stress release of surrounding rock with the passage of time should be considered. 
(4) The new liquid accelerator and its matching spraying technology can effectively reduce resilience and dust in the construction, the resilience rate is less than $10 \%$, save the cost, improve the environment, enhance the shotcrete strength, have good popularization using value.

\section{Acknowledgements}

The authors would like to thank the National Natural Science Foundation of China (Grant No. 51179098, 51379113), the Specialized Research Fund for the Doctoral Program of Higher Education of China (Grant No. 20120131110031), and the Fundamental Research Funds of Shandong University (2014YQ005).

\section{References}

[1] GUAN Baoshu. Technique of shotcrete support for tunnel and underground works[M]. Beijing: China Communications Press, (2009).

[2] ZHU Guangbing. Progress of the research for shotcrete[J]. Concrete, (2011), 258(4): 105-109.

[3] CHENG Liangkui. Shotcrete[M]. Beijing: China Architecture and Building Press, 1990.

[4] FENG Hao, ZHU Qingjiang. Handbook of engineering application of concrete admixture[M]. Beijing: China Architecture \& Building Press, (2005).

[5] CHANG Yanting. The influences of the early age properties of shotcrete on tunnel lining[J]. Journal of Yangtze River Scientific Research Institute, (1992), 9(3): 8-16.

[6] Oreste P.P, Peila.D. Modeling progressive hardening of shotcrete in convergence-confinement approach to tunnel design [J]. Tunneling and Underground Space Technology, (1997), 12(3): 425-431.

[7] SHEN Wei. Cement technology[M]. Wuhan: Wuhan University of Technology Press, (2012).

[8] LI Guoxin, LI Chunmei, ZHOU Wenying, WU Yonghua. Factors affecting the liquid sodium aluminate accelerated agent[J]. Concrete, (2005), (7): 54-58.

[9] ZHANG Yong, HE Tingshu, The influences of synthetic technology parameters on the properties of liquid aluminate accelerating additive[J]. Concrete, (2005), (4): 38-41.

[10] LI Guoxin, SONG Xuefeng, Synergistic effects of some other ingredients on liquid sodium aluminate accelerated agent[J]. Concrete, (2005), (4): 49-51.

[11] ZHANG Yong. Study on liquid aluminate accelerating additive[Master's Thesis][D]. Xi'an: Xi'an University of Architecture and Technology, (2005).

[12] Hae-Geun Park, Sang-Kyoung Sung, Chan-Gi Park, Jong-Pil Won. Influence of a C12A7 mineral-based accelerator on the strength and durability of shotcrete[J]. Cement and Concrete Research, (2008), 38(3): 379-385.

[13] Jong-Pil Won, Un-Jong Hwang, Cheol-Keun Kim, Su-Jin Lee. Mechanical performance of shotcrete made with a high-strength cement-based mineral accelerator[J]. Construction and Building Materials, (2013), 49: 175-183.

[14] C. Paglia, F. Wombacher, H. Bohni. The influence of alkali-free and alkaline shotcrete accelerators within cement systems Influence of the temperature on the sulfate attack mechanisms and damage[J]. Cement and Concrete Research, (2003), 33: 387-395.

[15] ZHAO Su, GUO Xinghua, XIA Yibing, ZUO Minghe. Study on the performance and mechanism of the liquid sodium aluminate accelerated agent[J]. Journal of Shenyang Jianzhu University (Natural Science), (2009), 25(6): 1125-1130.

[16] LI Gaoming. Regulation and mechanism of adjustable solidification agent on cement hydration process[Master's Thesis][D]. Wuhan: Wuhan University of Technology, (2011).

[17] CHEN Fengbin. Application and mechanism of initial support and surrounding rock in weak rock tunnel[PhD Thesis][D]. Beijing: Beijing Jiaotong University, (2012).

[18] LIU Baoguo, DU Xuedong. Visco-elastical analysis on interaction between supporting structure and surrounding rocks of circle tunnel[J]. Chinese Journal of Rock Mechanics and Engineering, (2004), 23(4): 561-564. 